\title{
Production Chains in an Interregional Framework: \\ Identification by Means of Average Propagation Lengths
}

\author{
Erik Dietzenbacher $^{\mathrm{a}, \mathrm{b}}$ and Isidoro Romero ${ }^{\mathrm{c}}$
}

a) Faculty of Economics, University of Groningen, P.O. Box 800, NL-9700 AV Groningen, The Netherlands, e-mail: e.dietzenbacher@eco.rug.nl;

b) Regional Economics Applications Laboratory (REAL), University of Illinois at Urbana-Champaign;

c) University of Seville, Faculty of Economics and Business Sciences, Applied Economics I Department, Av\ Ramón y Cajal, P. C. E-41018, Seville, Spain, e-mail: isidoro@us.es.

Please, quote the published version of this paper in the International Regional Science Review, Vol. 30. № 4, pp. 362-383.

\begin{abstract}
:
When linkages between industries are studied from the perspective of production chains, sequencing is important. In this respect, both the strength of the linkages and the distance between industries are relevant. Distance is measured by the average propagation length, defined as the average number of steps it takes a stimulus in one industry to propagate and affect another industry. Using the 1985 intercountry input-output table for six European countries, we present three applications. These are, visualizing the production structure by graphing its production chains, analyzing intercountry linkages between industries, and determining the role that each country plays within the system.
\end{abstract}

Key words: Input-output analysis, production chains, linkages

JEL codes: C67, D57, R15

\section{Acknowledgements:}

An earlier version of this paper was presented at the University of Illinois at UrbanaChampaign. The comments by Geoffrey J.D. Hewings and Edward Feser are gratefully acknowledged. 


\section{Introduction}

Product or supply chains give a detailed description of all the steps taken in the production process of a good or service. This runs from the initial phase to the final product. Typically, supply chains are studied for a single good and recently enterprise input-output models (see e.g. Polenske and Chen, 1991; Tang et al., 1994; Polenske, 1997; Grubbström and Tang, 2000; Marangoni and Fezzi, 2002; Polenske and McMichael, 2002) have been suggested for their analysis (see Albino et al., 2002, 2003). In life-cycle assessments, the scope is further extended by considering products from the cradle to the grave, focusing on material and energy requirements and environmental issues, such as emissions and disposals of solid waste (see e.g. Joshi, 2000).

This paper aims at describing or visualizing the production processes in a group of national economies using an interregional (or intercountry) framework. ${ }^{1}$ We adopt the underlying concept of sequencing in supply chains by viewing production as a stepwise procedure. In line with the ideas of the Austrian school in economics, some industries should be placed in an early stage and other industries in a later stage, when analyzing the production processes. ${ }^{2}$ A detailed overview of the production processes would require an in-depth study of all product chains. However, many different goods and services are produced and each industry is involved in a large set of product chains. An adequate description of the supply chains of all goods and services in an economy is therefore impossible. Even if input-output tables at their most detailed level (which comprise some 500 industries/commodities) were used, this would be a formidable task. Also it should be noted that the classification in such tables still represents aggregates of groups of commodities, implying that the data cannot reflect "true" product chains. At the same

\footnotetext{
${ }^{1}$ Using input-output tables, several approaches have been proposed in the past (see Dietzenbacher and Lahr, 2001, for an overview). These include graph theory (Yan and Ames, 1965; Blin and Murphy, 1974), structural path analysis (Defourney and Thorbecke, 1984; Sonis et al., 1995, 1997a, b; Sonis and Hewings, 1998a, b, 2001), network flow theory (Slater, 1978; Olsen, 1992), cluster analysis (Loviscek, 1982; Hoen, 2002a), or qualitative input-output analysis (Aroche-Reyes, 2001; Schnabl, 1994, 2001; see de Mesnard, 1995, 2001, for a critique).

${ }^{2}$ Within an input-output framework this gave rise to the issue of triangularization. By re-numbering the industries (i.e. permuting the rows and columns), the aim is to find a hierarchy that leads from primary products to final goods. Ideally, this yields an input matrix that shows only zeros on one side of the main diagonal (see, for example, Simpson and Tsukui, 1965; Fukui, 1986; Howe, 1991; Haltia, 1992).
} 
time, the question arises whether this level of detail is desirable to get a visualization of the production processes.

In this paper we will not study separate product chains. Instead, we aim at finding chains in the national and intercountry production structures. These chains are termed production chains, in contrast to product chains that focus on a single product. In order to sketch the methodology that we have used, consider the following simple example. The agricultural industry supplies a large part of its production to food processing, which in its turn is a major supplier for hotels and restaurants. There are direct links between agriculture and food processing and between food processing and hotels and restaurants. The link between agriculture and hotels and restaurants is indirect (via food processing). In determining this production chain, two aspects are important. First, the strength of the various links and, second, the number of the steps.

Measuring the strength of the links between industries has led to a substantial body of literature. ${ }^{3}$ Various alternative measures have been proposed for such interindustry linkages. One of the ways to distinguish between linkage measures is by asking whether they go through the production chain in a backward or a forward fashion. If, for example, consumers make more use of hotels and restaurants, this industry requires more products from the food processing industry, which in its turn needs more inputs from agriculture. In analyzing the linkages, note that hotels and restaurants depend on their purchases from food processing, which itself depends on inputs from agriculture. The dependencies in this backward approach are clearly buyers' dependencies. In the same way, we may trace a cost-push in agriculture in a forward fashion through the production chain to affect the total output value of hotels and restaurants. In this case, agriculture depends on its sales to food processing, which depends on its sales to hotels and restaurants. The dependencies in this forward approach are sellers' dependencies.

It should be stressed that these two approaches yield very different outcomes, in general. As an example, suppose that hotels and restaurants (with an output value of 1000 dollars) buy for 300 dollars from food processing (with an output value of 3000 dollars). Hence, inputs that are worth $30 \%$ of the output value of hotels and restaurants are bought

\footnotetext{
${ }^{3}$ Recent overviews of the literature can be found in Dietzenbacher and Lahr (2001); Sánchez-Chóliz and Duarte (2003); or Cai and Leung (2004).
} 
from food processing, while food processing sells only $10 \%$ of its outputs to hotels and restaurants. The (direct) backward dependence of hotels and restaurants on food processing is thus much larger than the (direct) forward dependence of food processing on hotels and restaurants. For the determination of production chains, however, both aspects need to be taken into account.

The second aspect is the number of steps or distance between the industries. In the example above, the case is simple because there are only three industries and no direct link between agriculture and hotels and restaurants. In general, however, input-output tables show that each industry sells something to every other industry and to itself. Therefore, each industry has a direct link with every other industry (although many of these links may be small in size). To measure the distance between industries, we will use the so-called average propagation length (APL). Taking the backward-looking approach, the APL measures for example the average number of steps it takes a final demand increase in hotels and restaurants to propagate throughout the production process and affect the output value in agriculture (see also Sonis et al., 1996). In the forward-looking approach, it measures the average number of steps it takes a cost-push in agriculture to affect the output value of hotels and restaurants. The advantage of APLs is that both approaches yield exactly the same answer. So, the distance between agriculture and hotels and restaurants does not depend on whether the forward or backward perspective is adopted.

In the next section, we will present our methodology and introduce the details of the APLs. Our empirical applications employ the intercountry input-output table of 1985 for six European countries and are discussed in Section 3. First, we analyze the average APLs for the six countries and their aggregate, and present a graphical representation of the production chains in the aggregate production structure. Second, we use APLs to study the intercountry linkages between industries. Third, we apply the hypothetical extraction method in connection with APLs to determine the role that each country plays within the group of six. Section 4 summarizes and discusses further extensions of the methodology and further applications. 


\section{Methodology}

For the ease of exposition, we will describe the methodology that we have used for the case of a national input-output table with $n$ industries. Specific details for interregional tables will be dealt with when we discuss the empirical application. Let $z_{i j}$ (the typical element of the matrix $\mathbf{Z}$ ) denote the domestic intermediate deliveries (in money terms) from industry $i$ to industry $j$. The typical element $f_{i}$ of column vector $\mathbf{f}$ denotes the final demand for the goods and services produced by industry $i$. Final demands include domestic consumption, domestic investments, government expenditures, and gross exports. The typical element $w_{j}$ of the row vector $\mathbf{w}^{\prime}$, gives the primary inputs of industry $j$, which include labor costs, capital depreciation, the operating surplus, and imports. The two accounting equations then yield

$$
\begin{aligned}
& \mathbf{x}=\mathbf{Z e}+\mathbf{f} \\
& \mathbf{x}^{\prime}=\mathbf{e}^{\prime} \mathbf{Z}+\mathbf{w}^{\prime}
\end{aligned}
$$

where $\mathbf{x}$ denotes the vector of gross domestic output values in each industry and $\mathbf{e}$ is the column summation vector consisting of ones.

From the backward-looking perspective, define input coefficients as $a_{i j}=z_{i j} / x_{j}$, or in matrix notation as $\mathbf{A}=\mathbf{Z} \hat{\mathbf{x}}^{-1}$, where $\hat{\mathbf{x}}$ denotes the diagonal matrix with the elements of the vector $\mathbf{x}$ on its main diagonal. The coefficient $a_{i j}$ gives the input from industry $i$ that is necessary per dollar of output in industry $j$. It also reflects the direct backward linkage or dependence of industry $j$ on inputs from industry $i$. Using the input coefficients, accounting equation (1) can be rewritten as

$$
\mathbf{x}=\mathbf{A x}+\mathbf{f}
$$

The solution of this equation yields 


$$
\mathbf{x}=(\mathbf{I}-\mathbf{A})^{-1} \mathbf{f}=\mathbf{L} \mathbf{f}
$$

where $\mathbf{L} \equiv(\mathbf{I}-\mathbf{A})^{-1}$ denotes the Leontief inverse. If the input coefficients remain the same, in increase $\Delta \mathbf{f}$ in final demands, would require that production is increased by $\Delta \mathbf{x}=\mathbf{L}(\Delta \mathbf{f})$. Taking the $j$ th unit vector for $\Delta \mathbf{f}$, immediately gives the interpretation of the Leontief inverse. That is, its typical element $l_{i j}$ gives the (extra) output in industry $i$, that is necessary to satisfy one (extra) dollar of final demand in industry $j$.

The elements of $\mathbf{L}$ are often taken as measures for the total (or direct plus indirect) linkages. Consider what happens to the output in industry $i$, if the final demand in industry $j$ increases by one dollar. First of all, this extra final demand must be produced, so that the output in industry $j$ increases by 1 . Second, in order to increase the output in industry $j$ by 1 , this industry requires inputs from all the other industries. These inputs need to be produced so that the output in industry $i$ increases by $a_{i j}$. This reflects the direct effect. In the same way, the output in any industry $k$ increases by $a_{k j}$. But if the output in industry $k$ increases, it requires extra inputs from industry $i$ to the amount of $a_{i k} a_{k j}$. This holds for each industry $k$ so that the output in industry $i$ must be increased by $\Sigma_{k} a_{i k} a_{k j}$. This is a two-step indirect effect. The two-step indirect effect increases the output in industry $k$ by $\Sigma_{m} a_{k m} a_{m j}$, which requires extra inputs $a_{i k} \Sigma_{m} a_{k m} a_{m j}$ from industry $i$. Summing over $k$ gives the three-step indirect effect for industry $i$ as $\Sigma_{k} \Sigma_{m} a_{i k} a_{k m} a_{m j}$. And so forth.

The total increase in the output of industry $i$ is obtained by collecting all the terms and yields

$$
\Delta x_{i}=l_{i j}=a_{i j}+\Sigma_{k} a_{i k} a_{k j}+\Sigma_{k} \Sigma_{m} a_{i k} a_{k m} a_{m j}+\ldots
$$

where the first term expresses the direct effect and the other terms the indirect effects. Note that the terms in (5) are equal to the element $(i, j)$ of the matrices $\mathbf{A}, \mathbf{A}^{2}, \mathbf{A}^{3}$, and so forth. In the case $i=j$, also the so-called initial effect must be included because the extra final demand must first of all be produced itself. In that case, expression (5) changes into 


$$
\Delta x_{j}=l_{j j}=1+a_{j j}+\Sigma_{k} a_{j k} a_{k j}+\Sigma_{k} \Sigma_{m} a_{j k} a_{k m} a_{m j}+\ldots
$$

Clearly, this is in line with the power series expansion of the Leontief inverse. That is, $\mathbf{L} \equiv(\mathbf{I}-\mathbf{A})^{-1}=\mathbf{I}+\mathbf{A}+\mathbf{A}^{2}+\mathbf{A}^{3}+\ldots$ and, hence,

$$
\Delta \mathbf{x}=\mathbf{L}(\Delta \mathbf{f})=\left(\mathbf{I}+\mathbf{A}+\mathbf{A}^{2}+\mathbf{A}^{3}+\ldots\right)(\Delta \mathbf{f})
$$

Taking the $j$ th unit vector for $\Delta \mathbf{f}$ yields equations (5) and (6).

Next we derive the average propagation length (APL) between industries $i$ and $j$, extending the technique proposed in Harthoorn (1988). If the final demand in industry $j$ increases by 1 , the output in industry $i$ is affected by $\Delta x_{i}=l_{i j}$. From (5) it follows that the share $a_{i j} / l_{i j}$ requires one step, the share $\Sigma_{k} a_{i k} a_{k j} / l_{i j}$ two steps, the share $\Sigma_{k} \Sigma_{m} a_{i k} a_{k m} a_{m j} / l_{i j}$ three steps, etcetera. The average number of steps it takes the final demand increase in industry $j$ to affect the output in industry $i$, thus becomes

$$
\left(1 \times a_{i j}+2 \times \Sigma_{k} a_{i k} a_{k j}+3 \times \Sigma_{k} \Sigma_{m} a_{i k} a_{k m} a_{m j}+\ldots\right) / l_{i j}
$$

In the case where $i=j$, a similar reasoning applies. Because the initial effect occurs irrespective of the production structure, it does not provide any information on the dependencies and will be neglected (se, for example, Beyers, 1983). ${ }^{4}$ So, a final demand increase by one in industry $j$ yields (next to the initial effect) an increase in this industry's output of $\Delta x_{j}-1=l_{j j}-1$. Using expression (6) gives for the APL

$$
\left(1 \times a_{j j}+2 \times \Sigma_{k} a_{j k} a_{k j}+3 \times \Sigma_{k} \Sigma_{m} a_{j k} a_{k m} a_{m j}+\ldots\right) /\left(l_{j j}-1\right)
$$

\footnotetext{
${ }^{4}$ Alternatively, the initial effect could be considered to have length 0 . In that case, the term $0 \times 1$ needs to be added in the numerator in (8) and the denominator is to be replaced by $l_{j j}$. A consequence is that the APLs on the main diagonal of Table 2 below, will become close to zero, indicating that the initial effect dominates (in size) the direct and indirect effects.
} 
Note that the numerator in expressions (7) and (8) is given by the elements $(i, j)$ and $(j, j)$ of the matrix $\mathbf{H}=1 \times \mathbf{A}+2 \times \mathbf{A}^{2}+3 \times \mathbf{A}^{3}+\ldots=\sum_{t=1}^{\infty} t \mathbf{A}^{t}$. Premultiplying $\mathbf{H}$ by $(\mathbf{I}-\mathbf{A})$ gives $(\mathbf{I}-\mathbf{A}) \mathbf{H}=\mathbf{A}+\mathbf{A}^{2}+\mathbf{A}^{3}+\ldots=\mathbf{L}-\mathbf{I}$. Hence $\mathbf{H}=\mathbf{L}(\mathbf{L}-\mathbf{I}) .{ }^{5}$ The APLs are thus obtained as $h_{i j} / l_{i j}$ for $i \neq j$ and as $h_{j j} /\left(l_{j j}-1\right)$.

Next we consider the forward-looking approach. Using the sellers' perspective, output coefficients are defined as $b_{i j}=z_{i j} / x_{i}\left(\right.$ or $\left.\mathbf{B}=\hat{\mathbf{x}}^{-1} \mathbf{Z}\right)$, which gives the share of the output of industry $i$ that is sold to industry $j$. It reflects the direct forward dependence of industry $i$ on sales to industry $j$. Accounting equation (2) can now be rewritten as $\mathbf{x}^{\prime}=\mathbf{x}^{\prime} \mathbf{B}+\mathbf{w}^{\prime}$ and its solution yields $\mathbf{x}^{\prime}=\mathbf{w}^{\prime}(\mathbf{I}-\mathbf{B})^{-1}=\mathbf{w}^{\prime} \mathbf{G}$. Assuming that the output coefficients remain unchanged, an exogenous change $\Delta \mathbf{w}^{\prime}$ in the primary inputs affects the gross output values as $\Delta \mathbf{x}^{\prime}=\left(\Delta \mathbf{w}^{\prime}\right) \mathbf{G}$. This model is well known as the supply-driven input-output model proposed by Ghosh (1958). Although the model produced intuitively appealing results in empirical analyses (e.g. Davis and Salkin, 1984), it has been heavily criticized and became regarded as theoretically implausible (see Oosterhaven, 1988, 1989). Dietzenbacher (1997), however, showed that all implausibilities vanish once the model is interpreted as a price model instead of as a quantity model (which had been the typical interpretation). In that case, the elements of the Ghosh inverse $\mathbf{G} \equiv(\mathbf{I}-\mathbf{B})^{-1}$ can be given the following interpretation. If the costs of the primary inputs in industry $i$ increase by 1 dollar, the gross output value in industry $j$ increases by $g_{i j}$ dollars. The reasoning is that in order to cope with the increased costs, industries must increase their prices to ensure the model's underlying equality between revenues and costs. Leaving the quantities unchanged, this implies that the output values will increase. As a matter of fact, it can be shown that there is a one-to-one correspondence between the Ghosh model and the standard Leontief price model.

The element $g_{i j}$ reflects the total (or direct plus indirect) dependence of industry $i$ on industry $j .{ }^{6}$ From the power series expansion of the Ghosh inverse we have

\footnotetext{
${ }^{5}$ In the same way, it follows from $\mathbf{H}(\mathbf{I}-\mathbf{A})=\mathbf{L}-\mathbf{I}$ that $\mathbf{H}=\mathbf{L}(\mathbf{L}-\mathbf{I})$. Using $\mathbf{L}-\mathbf{I}=\mathbf{A} \mathbf{L}=\mathbf{L A}$ provides a set of alternative expressions for $\mathbf{H}$.

${ }^{6}$ The matrices B and $\mathbf{G}$ have been proposed before to reflect the forward linkages, see e.g. Beyers (1976), Jones (1976), Dietzenbacher (1992).
} 
$\mathbf{G}=\mathbf{I}+\mathbf{B}+\mathbf{B}^{2}+\mathbf{B}^{3}+\ldots$ In deriving the APL between industries $i$ and $j(\neq i)$, consider an increase the primary costs of industry $i$ by one dollar. The output value in industry $j$ increases by $\Delta x_{j}=g_{i j}=b_{i j}+\Sigma_{k} b_{i k} b_{k j}+\Sigma_{k} \Sigma_{m} b_{i k} b_{k m} b_{m j}+\ldots$. The first term gives the (onestep) direct effect, the second term the two-step indirect effect, the third term the threestep indirect effect, etcetera. The average number of steps it takes a cost-push in industry $i$ to affect the output value in industry $j$ is thus given by

$$
\left(1 \times b_{i j}+2 \times \Sigma_{k} b_{i k} b_{k j}+3 \times \Sigma_{k} \Sigma_{m} b_{i k} b_{k m} b_{m j}+\ldots\right) / g_{i j}
$$

The numerator can be written as $\tilde{h}_{i j}$, with $\tilde{\mathbf{H}}=\mathbf{G}(\mathbf{G}-\mathbf{I})$, and the APLs are given by $\tilde{h}_{i j} / g_{i j}$. When $i=j$, the APLs are (similar to backward-looking case) given by $\tilde{h}_{j j} /\left(g_{j j}-1\right)$ due to neglecting the initial effect.

Finally, we show that the APLs are the same for the forward and the backward case. From the definition of the input and the output coefficients it follows that $b_{i j}=a_{i j} x_{j} / x_{i}, \quad$ or $\quad \mathbf{B}=\hat{\mathbf{x}}^{-1} \mathbf{A} \hat{\mathbf{x}}$. As a consequence we have $\mathbf{G}=(\mathbf{I}-\mathbf{B})^{-1}=\hat{\mathbf{x}}^{-1}(\mathbf{I}-\mathbf{A})^{-1} \hat{\mathbf{x}}=\hat{\mathbf{x}}^{-1} \mathbf{L} \hat{\mathbf{x}} \quad$ and $\quad$ also $\quad \mathbf{G}-\mathbf{I}=\hat{\mathbf{x}}^{-1}(\mathbf{L}-\mathbf{I}) \hat{\mathbf{x}} . \quad$ Therefore $\tilde{\mathbf{H}}=\mathbf{G}(\mathbf{G}-\mathbf{I})=\hat{\mathbf{x}}^{-1} \mathbf{L}(\mathbf{L}-\mathbf{I}) \hat{\mathbf{x}}=\hat{\mathbf{x}}^{-1} \mathbf{H} \hat{\mathbf{x}}$. That is, $\tilde{h}_{i j}=h_{i j} x_{j} / x_{i}$ and $g_{i j}=l_{i j} x_{j} / x_{i}$. For the

APL in the forward case we thus find $\tilde{h}_{i j} / g_{i j}=h_{i j} / l_{i j}$, which is the APL in the backward case.

\section{Application to the 1985 intercountry input-output table for six European countries}

For our empirical analysis, we have used the intercountry input-output table for 1985, for six European countries. The included countries are: Germany $(\mathrm{G})$, France (F), Italy (I), the Netherlands (N), Belgium (B), and Denmark (D). The table is constructed by combining the harmonized national input-output tables (see Eurostat, 1979) of the six 
countries. In these tables the domestic transactions are valued in producers' prices, and the imports in ex-customs prices. Furthermore, the imports are distinguished into two origins: imports from within and imports from outside the EU. To obtain the intercountry tables, firstly the imports from within the EU have been disaggregated into country of origin, using international trade data. Secondly, to the thus obtained table of bilateral transactions, the RAS method has been applied, so as to reassess the ex-customs valuation of intra-EU imports approximately into producers' prices. The full details of the construction method are given in van der Linden (1999), a summary is given by van der Linden and Oosterhaven (1995). ${ }^{7}$

The resulting table covers 25 industries and is a full interregional type of table. That is, all deliveries $z_{i j}^{r s}$ from industry $i$ in country $r$ to industry $j$ in country $s$ are available. For our purpose of sketching the chains in the production structure, the original 25industry level provides too many details that blur the picture. Therefore, we have further aggregated the table to the following 8 industries. Agriculture (AG), Energy (EN), Metalrelated manufacturing (ME), Agro-related manufacturing (AM), Building and construction (BU), Other manufacturing (OM), Market services (MS), and Public services (PS). This implies that the starting-point for our calculations is a $48 \times 48$ matrix $\mathbf{Z}$ of intermediate deliveries. This matrix can be partitioned as follows

$$
\mathbf{Z}=\left[\begin{array}{llllll}
\mathbf{Z}^{G G} & \mathbf{Z}^{G F} & \mathbf{Z}^{G I} & \mathbf{Z}^{G N} & \mathbf{Z}^{G B} & \mathbf{Z}^{G D} \\
\mathbf{Z}^{F G} & \mathbf{Z}^{F F} & \mathbf{Z}^{F I} & \mathbf{Z}^{F N} & \mathbf{Z}^{F B} & \mathbf{Z}^{F D} \\
\mathbf{Z}^{I G} & \mathbf{Z}^{I F} & \mathbf{Z}^{I I} & \mathbf{Z}^{I N} & \mathbf{Z}^{I B} & \mathbf{Z}^{I D} \\
\mathbf{Z}^{N G} & \mathbf{Z}^{N F} & \mathbf{Z}^{N I} & \mathbf{Z}^{N N} & \mathbf{Z}^{N B} & \mathbf{Z}^{N D} \\
\mathbf{Z}^{B G} & \mathbf{Z}^{B F} & \mathbf{Z}^{B I} & \mathbf{Z}^{B N} & \mathbf{Z}^{B B} & \mathbf{Z}^{B D} \\
\mathbf{Z}^{D G} & \mathbf{Z}^{D F} & \mathbf{Z}^{D I} & \mathbf{Z}^{D N} & \mathbf{Z}^{D B} & \mathbf{Z}^{D D}
\end{array}\right]
$$

The $8 \times 8$ submatrices $\mathbf{Z}^{r r}$ give the domestic deliveries within country $r=G, F, I, N, B$, $D$. The $8 \times 8$ submatrices $\mathbf{Z}^{r s}$ give the deliveries from country $r$ that are used as inputs in country $s$ (with $r, s=G, F, I, N, B, D$ ). Note that the imports from the rest of the world

\footnotetext{
${ }^{7}$ The full series of European intercountry input-output tables in current prices (for the years 1965, 1970, 1975, 1980, and 1985) can be downloaded at http://www.regroningen.nl. For the intercountry tables in constant prices, see Hoen (2002b).
} 
are included in the primary inputs. The exports of country $r$ to private consumers or investors in one of the other five countries, as well as all exports to the rest of the world are included in the final demand vector of country $r$.

\subsection{National and aggregate results}

As a first exercise, we consider the national results and the results for the aggregate of the entire region. That is, we have calculated the APLs on the basis of the domestic deliveries $\mathbf{Z}^{r r}$ for each country $r$ separately. Also, we have aggregated the six countries as if they were a single region or country, using $\mathbf{Z}^{A G G R}=\sum_{r} \Sigma_{s} \mathbf{Z}^{r s}$. Table 1 gives for each of the seven cases the average APL and the largest APL that was found. The average APL for the aggregate table equals 2.06, which can be interpreted as a measurement of the average length of production chains. Note that the average and maximum APL are larger for the aggregate table than for any of the separate countries. This is in line with the intuition because at a national level there will be fewer and smaller domestic linkages than at the aggregate level. At a national scale of analysis the identified production chains may therefore be expected to be shorter than in the case where international linkages are included.

A similar observation arises when we compare the separate country results. A clear distinction can be made between the three large countries (Germany, France and Italy) and the three small countries (the Netherlands, Belgium and Denmark). The large countries have a production structure that relies much more on itself than the small countries do. The small countries depend much more on inputs from other countries (including the three large partners), so that their domestic linkages will be smaller and fewer. This is reflected by shorter domestic production chains. In this respect, it is interesting to note that Denmark's average APL is fairly large given its size. A similar observation was made by Dietzenbacher and van der Linden (1997), i.e. Denmark being surprisingly self-supporting for such a small economy and therefore behaving as if it were much larger than it actually is. The relationship of scale and the degree of selfsupport on the one hand and the average size of the APLs on the other hand, is also confirmed by a preliminary analysis to test the methodology. Dietzenbacher et al. (2005) 
found that for Andalusia (a region in the south of Spain) the average APL was 1.56 and the maximum was 2.64. The calculations were based on the intraregional deliveries in the 1995 Andalusian input-output table, distinguishing six industries.

The APLs as calculated from the aggregate input-output table for the six countries are given in Table 2. Note that it follows from the definition that the APL between two different industries cannot be smaller than one (and typically is larger than one). The same holds for the APL between an industry and itself. An APL close to one reflects that the dependence is primarily direct and indirect linkages play a minor role. Although we will focus primarily on the APLs between two different industries when determining the production chains, it is interesting to observe that the lowest APL values are found principally on the diagonal, i.e. from an industry to itself. This indicates that the selfdependence of the industries is very direct. Due to the substantial aggregation, each industry consists of many subindustries. It turns out that subindustries within any industry $i$ exhibit a strong direct dependence on other subindustries in the same industry. The dependence is thus not brought about via one (or more) other industries, implying that the interindustry feedbacks (see Dietzenbacher and van der Linden, 1997) are very small.

In analyzing the results in Table 2, recall that each figure has a double interpretation. For example, the APL of 3.49 in the row AG and the column EN indicates the average propagation length of a cost-push in agriculture to affect the output value in energy. It deals with the dependence (which is directed forward) of agriculture on energy. At the same time, however, it gives the average propagation length of a demand-pull (which is directed backward) from energy to agriculture. So, each figure may be interpreted in two directions. In order to avoid any confusion, we will use the terminology forward APL or backward APL, depending on the type of interpretation. For example, the value 3.49 above gives the forward APL from AG to EN or, similarly, the backward APL from EN to AG. The lowest forward APLs $(<1.60)$-neglecting the selfdependencies- are found from other manufacturing to building; from building to energy; from building to market services; and from building to public services. The highest forward APL values (> 3.00) are those from agriculture to energy; from agriculture to metal-related manufacturing; and from agriculture to building. 
The averages are useful to obtain a general idea of the role that a certain industry plays. Consider first the column with the row-average of all forward APLs of any industry. Note that the APLs in a single row reflect all forward dependencies of that industry. The largest row-average is found for agriculture and the smallest for public services. The forward APLs of agriculture (and its row-average) show that its dependencies are highly indirect, with the exception of the dependence on agro-related manufacturing (with an APL of 1.60). Agriculture can be seen as an industry that is situated in the early stage of a production chain, with several stages following afterwards and agro-related manufacturing being involved in the next stage. For public services, with the smallest row-average, the opposite holds. Public services are principally oriented towards final demands and this industry does not have important forward linkages.

In the row with column-averages, the largest value is found for metal-related manufacturing. Recall that any column of APLs corresponds to the backward dependencies of that industry. Metal-related manufacturing is thus found to have indirect backward dependencies with (on average) the largest number of steps. This industry is thus situated at the end of the corresponding production chains. The smallest columnaverage is observed for public services, indicating the absence of long production chains that lead to this industry.

Summarizing, a large row-average (indicating the forward APLs) and/or a small column-average (indicating the backward APLs) for an industry, suggests that this industry is located at the beginning of a (set of) production chains(s). A small rowaverage and/or a large column-average points at a place near the end of some production chain. The case of public services, however, points out that we should be careful in focusing only on APLs. Observe that the findings are contradictory. The small rowaverage suggests that this industry is located at the end of a chain, while the small column-average suggests the opposite. Of course, given their role and orientation towards final demands, no-one would situate public services at the beginning of a production chain. It turns out that this industry essentially has only very small linkages (as will become apparent in Table 3 below).

As we have seen, low (resp. high) APL values tell us that the effect from one industry to another is primarily direct (resp. indirect). It should be born in mind, however, 
that this holds irrespective of the importance (i.e. size) of the total effect. APLs thus provide useful information on the length of the linkages, whenever such linkages are felt to be relevant. The case of public services, however, shows that APLs may lead to contradictory and implausible conclusions when the linkages are small. This suggests that APLs be applied to identify production chains, only in cases where the size of the linkages is sufficiently large.

Taking the size (or strength) of the linkages into account can be done in various ways, because many measures for linkages have been proposed. In line with the development of the APL, our choice is based on the total size of the effect of a cost-push and the effect of a demand-pull. Neglecting the initial effects (as we have done in Section 2 ), these effects are obtained from the matrices $\mathbf{G}-\mathbf{I}$ and $\mathbf{L}-\mathbf{I}$, respectively. Recall that one of the attractive features of APLs was that it did not matter whether the forward approach of a cost-push was considered or the backward approach of a demand-pull. We would like to retain this property also when measuring the size of the linkages. So, instead of using the Leontief inverse for the backward linkages and the Ghosh inverse for the forward effects, we have used the average to take both directions into account. The linkages are given by the elements of the matrix $\mathbf{F}$, which is defined as follows.

$$
\mathbf{F}=\frac{1}{2}[(\mathbf{G}-\mathbf{I})+(\mathbf{L}-\mathbf{I})]
$$

The element $f_{i j}$ gives the size of the linkage and equals the average of the forward effect of a cost-push in industry $i$ on the output value in industry $j$ and the backward effect of a demand-pull in industry $j$ on the output in industry $i$. The matrix $\mathbf{F}$, as calculated on the basis of the aggregate input-output table for the six countries, is given in Table 3 . Note that the figures in the row and the column for public services are all very small, except for the element corresponding to the purchase of inputs from market services and the diagonal element indicating their self-dependency.

Closer inspection of the numbers in Tables 2 and 3 suggests that there is an inverse relationship between the APLs and the size of the linkages as given by the elements $f_{i j}$. The Pearson correlation coefficient turns out to be equal to -0.570 . Hence, 
lower APL values are, to some extent, associated with stronger linkages. This implies that the largest impacts between two industries are often those that are essentially direct.

The limitation of focusing entirely on the matrix $\mathbf{F}$, is that it does not allow to distinguish whether some linkage is mainly direct or indirect. In the latter case, the transmission from one industry to another takes at least two steps. APLs indicate the "distance" between two industries by expressing the average number of steps it takes to transmit a cost-push (or demand-pull) from one industry to the other. The limitation of focusing entirely on APLs, is that the size (and thus the relevance) of the transmission itself may be negligible. In order to visualize the production structure in terms of production chains, both aspects (i.e. relevance of the linkages and distance between industries) are important.

The obvious solution is thus to combine the two types of indicator. That is, we take APLs into account only if the linkage is sufficiently large, using a threshold value $a$. Further, the APLs are rounded down (or truncated) to the nearest integer. This gives us the distances of the relevant linkages. Taking a threshold value $a=0.130$, this results in Table 4. Note that all relevant linkages (i.e. with $f_{i j} \geq a$ ) are printed in Table 3 in bold italics. Entries $(i, j)$ that are zero in Table 4, correspond therefore to linkages that are considered to be too small.

A graphical representation of Table 4 is given by Figure 1. Each arrow represents a relevant linkage and gives the (truncated or rounded down) APL. Solid arrows have an APL of 1, and dotted arrows have an APL of 2. They are termed APL-1 and APL-2 linkages, respectively. Note that the industry's self-dependence - which is larger than the threshold value in all industries except building and construction - has been left out. Further, it should be emphasized that the arrows indicate the APLs from a forward perspective. That is, the arrow from e.g. agriculture to agro-related manufacturing indicates the forward dependence of agriculture (in transmitting its cost-push) on agrorelated manufacturing. This is in line with the usual graphs for product chains.

Figure 1 shows a clear distinction between the industries. Agriculture and energy are, with only outgoing arrows, located in the beginning of the production chains. Agrorelated manufacturing, public services, building and construction, and metal-related manufacturing have only incoming arrows and are thus situated at the end of the 
production chains. Market services and other manufacturing take an intermediate position, having both incoming and outgoing arrows.

Disregarding the APL-2 linkages for the moment, Figure 1 shows that there are several production chains leading from energy to building, from energy to public services and from energy to metal-related manufacturing. In all three cases, other manufacturing and/or market services serve as intermediate steps. Also there is a chain from agriculture to agro-related manufacturing, which is connected to the other chains in the sense that agro-related manufacturing shows an APL-2 backward dependence on market services.

Figure 1 also shows that APL-2 linkages may be consistent with a sequence of APL-1 linkages, but there is no reason why this should always be the case. For example, metal-related manufacturing has a strong direct (i.e. APL-1) backward dependence on market services, which - in its turn - has a strong direct backward dependence on energy. Combining these two APL-1 linkages is in line with the reported APL-2 arrow from energy to metal-related manufacturing. In contrast to this, the APL-2 linkage between market services and agro-related manufacturing can not be "explained" from a simple combination of two APL-1 linkages. This case points at an accumulation of connections or routes. Each of them runs via one other industry and none of these routes is sufficiently important on its own, although they are important as a group (given the fact that this linkage passed the threshold and is reported as APL-2). A similar reasoning holds for the APL-2 linkage between other manufacturing and metal-related manufacturing. Also the opposite need not be the case. For example, Figure 1 shows that the connection between energy and building can be established by two routes based on APL-1 linkages. The first is through market services and the second via other manufacturing. Yet, it turns out that even together they are not strong enough to warrant an APL-2 linkage from energy to building.

\subsection{Intercountry linkages}

In order to study the interdependencies between industries in different countries, we have used the full intercountry input-output table. With six countries and eight industries, we calculated the $48 \times 48$ matrices with APLs and with linkages. As was expected, it appeared 
that the intercountry linkages are generally fairly weak when compared to the domestic (or intra-country) linkages. Hence, setting a high threshold will essentially yield domestic linkages. Adopting a sufficiently low threshold will provide the most relevant intercountry linkages, but the picture will be blurred by a very large set of domestic linkages. We have chosen a relatively low threshold value (0.030) and focus only on the intercountry linkages. That is, in our graphical representation and discussion any domestic linkage will be neglected, unless it provides relevant information for intercountry issues.

The intercountry linkages are shown in Figure 2 where we have re-grouped the linkages into four clusters. These are: a metal-related cluster (consisting of metal-related manufacturing and building and construction); an energy cluster (including also market services); an agro-related cluster (with agriculture and agro-related manufacturing); and other manufacturing. Note that no important linkages are found that involve public services. It is also interesting to observe that the central role as played by market services in Figure 1, now has almost completely vanished. The APL-2 connection between the German market services and Dutch energy is the only reported intercountry linkage (as the APL-1 connection with German energy is domestic). The limited role of market services for intercountry linkages and the absence of public services, clearly points at the domestic focus of these industries.

The results exhibit several interesting characteristics. First, almost all intercountry linkages are within a cluster. The only intercountry linkages between clusters are from energy in the Netherlands to German metal-related manufacturing, to German other manufacturing and to Belgian other manufacturing. These strong backward dependencies on the Dutch energy industry clearly reflect the huge amounts of exports of gas from the Netherlands. Second, within the clusters the intercountry linkages appear to be essentially of an intra-industry nature, except for those within the agro-related cluster. The only two interindusty linkages between two countries within the same cluster are from German metal-related manufacturing to Dutch building and construction, and from Dutch energy to German market services. The agro-related manufacturing cluster reports that the typical, strong forward dependence of agriculture on agro-related manufacturing is also found between countries. 
A third finding is that several intra-industry linkages between two countries are mutual. This is the case for metal-related manufacturing, other manufacturing and agrorelated manufacturing. Observe also that no mutual linkages are found for agriculture and energy, both of which are located at the beginning of production chains. Summarizing our findings, we have seen that intercountry linkages are either intra-industry or between agriculture and agro-related manufacturing, and intra-industry linkages are frequently mutual (except for industries in the early phase of a production chain).

Also for the intercountry linkages, we find that some of the APL-2 arrows are in line with the combination of two APL-1 links, while some others are not. For example, for the APL-2 forward dependence of the German on the French metal-related manufacturing, the Belgian metal-related manufacturing is an intermediate step. In several other cases in Figure 2, such APL-2 linkages can be "explained" if domestic APL-1 linkages are included. This applies to the APL-2 arrows from German metalrelated manufacturing to Dutch building and construction (via Dutch metal-related manufacturing); from Dutch energy to German market services (via German energy); from Dutch energy to German other manufacturing (via German energy); from Belgian agriculture to French agro-related manufacturing (via Belgian agro-related manufacturing); from Belgian agriculture to Dutch agro-related manufacturing (also via Belgian agro-related manufacturing); and from Dutch agriculture to Belgian agro-related manufacturing (via Dutch agro-related manufacturing). Note that also the APL-3 linkage between Dutch energy and German metal-related manufacturing is in line with sequencing three APL-1 linkages (using German energy and German other manufacturing as intermediate steps).

\subsection{Extracting countries}

The graphical representation in Figure 2 focused entirely on intercountry linkages, which allowed us to get some insight into the dependencies between the countries. A simple count of the incoming and outgoing arrows for each country indicates its role for the other countries. We find 23 for Germany and Belgium, 21 for the Netherlands, 13 for 
France, and 3 for Italy and for Denmark. ${ }^{8}$ This preliminary finding suggests that Germany and Belgium are important for the dependencies between countries, whereas Italy and Denmark are not.

One way to quantify the role of a single country within the system, is by means of the hypothetical extraction method. ${ }^{9}$ The underlying idea is that each country (one at a time) is extracted from the 6-country system. If for example Germany is extracted, the remaining system consists of five countries. The imports from and exports to Germany are treated in the same way as trade with the rest of the world. That is, these flows are not taken into account when analyzing the linkages within the 5-country system. The effect of extracting a country is that the remaining 5-country system shows less interactions and a lesser degree of complexity. The linkages will be weaker and fewer, so that the APLs will be smaller. The extent to which the APLs have decreased indicates the relevance of the extracted country within the original 6-country system.

For our application we have used the average APL. In the case of extracting Germany for example, the $40 \times 40$ matrix with APLs was calculated for the remaining group of five countries (and eight industries). This yields the average APL after extraction, which is to be compared with the average APL before extraction. The latter is based on the original $48 \times 48$ matrix of APLs for the full 6-country system. Note, however, that for reasons of comparability the average APL is determined only over the $40 \times 40$ APLs that do not involve Germany (i.e. the extracted country).

The results of extracting a country are given in Table 5. Before we discuss the findings in more detail, it should be emphasized that the size of the average APLs are quite different from those reported in Table 1. As a point of reference, the average APL as calculated from the full $48 \times 48$ matrix of APLs for the 6-country system amounts to 2.84. This is substantially larger than the value of 2.06 that was found for the aggregate in Table 1. This remarkable difference is caused by the difference in size of the input-output tables, i.e. $8 \times 8$ versus $48 \times 48$. Working with the $48 \times 48$ table means that, for example,

\footnotetext{
${ }^{8}$ Note that only intercountry linkages have been counted, not the domestic linkages in Figure 2.

${ }^{9}$ The hypothetical extraction method was originally proposed by Paelinck et al. (1965) and Strassert (1968) for extracting industries. In a regional context, the approach was introduced by Miller $(1966,1969)$ and Miller and Blair (1983). Recent applications include Groenewold et al. (1987, 1993); Dietzenbacher et al. (1993); Dietzenbacher and van der Linden (1997); Duarte et al. (2002); and Cai and Leung (2004). For an excellent overview, see Miller and Lahr (2001).
} 
German agriculture is a different industry than French agriculture. In Section 3.1, when working with the aggregate $8 \times 8$ table, these industries were part of a single agriculture industry. The single link in Section 3.1 between other manufacturing and energy, for example, now consists of 6 intra-country and 30 intercountry links. Consequently, the complexity of the production structure in terms of connections between industries is much larger, which is reflected by a much larger average APL. This also points at a potential drawback of using APLs. That is, the results of different studies should be compared only with the greatest care whenever they have employed a different number of industries.

Table 5 shows that extracting a country lowers the average APL of the remaining five countries. The APLs within the 5-country system are shortened because the linkages in which the extracted country participates are now considered as external and thus disregarded for calculating the APLs. Germany is by far the most important country in terms of its participation in the 6-country system. Also the extraction of Belgium, the Netherlands and France (in this order) reduces the average APL considerable. Extracting Italy and, in particular, Denmark is found to have only a small (respectively negligible) effect on the length of the chains.

\section{Concluding remarks}

In this paper we have studied linkages between industries from the perspective of production chains, so that sequencing plays an important role. Therefore, the distance between two industries is a relevant aspect, next to the strength of the linkage. Distance was expressed by the average propagation length (APL), which was defined as the average number of steps it takes a stimulus in one industry to propagate throughout the production structure and affect another industry (or itself).

Using the 1985 intercountry input-output table for six European countries, we have presented three types of application. First, we showed how combining APLs and linkage sizes allows for a visualization of the production structure by graphing the production chains. The APLs clearly pointed at sequencing the steps in the production 
processes. Second, we have applied the same methodology to get some insight in the intercountry linkages between the industries. It was found that most of the linkages where intra-industry (with the exception of the interindustry linkages between agriculture and agro-related manufacturing). We also observed that many of these intra-industry linkages were mutual for industries located in a later phase of the production chain. Industries in the early phase of the chain (such as agriculture and energy) only exhibited one-way dependencies. Third, we have applied the hypothetical extraction method to calculate the effect on the average APL. Extracting Germany decreased the average APL of the other five countries the most, which indicates that the linkages with and within Germany are the most important for the system of the six countries.

There are several directions in which the framework of average propagation lengths may be expanded. One is to incorporate the aspect of time more explicitly into this concept. For example, studying supply chains in the context of inventory control and material requirements planning, Grubbström and Ovrin (1992) use Laplace transforms to take timing into consideration. In our framework, we have used the power series expansion of the Leontief inverse to distinguish between e.g. one-step, two-step and three-step effects. Robinson and Markandya (1973) presented an input-output model where each step takes a certain amount of time (e.g. a month). They state (Robinson and Markandya, 1973, p. 121) that "systems are more 'complex' when they require more time and transactions to reach a new equilibrium after some exogenous change."

A second expansion would involve the application of the methodology to other fields. Examples would be the power structure (including relations and hierarchies) in social networks (see e.g. Burt, 1992), the property structure within groups of firms that have a silent interest in each other due to cross-shareholding (see e.g. Flath, 1993; Turnovec, 1999; or Dietzenbacher et al., 2000), or the issue of fragmentation in economic geography (see e.g. Jones and Kierzkowski, 2005). A more straightforward extension would be to consider APLs in the context of extended input-output models and demoeconomic models, taking for example interregional migration into account (see e.g. Batey and Rose, 1990; Madden and Trigg, 1990; Oosterhaven and Dewhurst, 1990).

Finally, it should be pointed out that the results obtained from applying APLs have a certain policy relevance. The arrows in our graphs indicate how an exogenous 
shock in one industry propagates and affects other industries. Suppose, for example, that the Dutch energy industry were struck by an unfortunate event that drastically reduces its capacity. Following the outgoing arrows in Figure 2 (indicating forward dependencies) shows that other manufacturing and metal-related manufacturing will be affected in each country. ${ }^{10}$ The effects of a final demand shock can be traced similarly in a backward fashion by following the incoming arrows in the opposite direction.

A further policy application arises when one particular industry is singled out, for example agriculture. In that case, it would make sense to calculate the results at a much more detailed level. For instance, in the context of the European intercountry application, we would have used the $150 \times 150$ matrix of intermediate deliveries, as based on 25 industries (instead of the eight aggregated industries). Table 4 would in this case record 150 rows and columns. However, because the focus would be solely on agriculture, essentially the non-zero elements in the six rows and columns for agriculture would be of particular interest. This would allow us to analyze the position of agriculture in each country and the connections with other industries and other countries. The results of such an investigation might be of help in addressing agricultural or rural policy issues (see e.g. Hewings, 2001).

\section{References}

Albino, V., Izzo, C. and Kühtz, S. (2002) Input-output models for the analysis of a local/global supply chain, International Journal of Production Economics, 78, pp. $119-131$.

Albino, V., Dietzenbacher, E. and Kühtz, S. (2003) Analysing materials and energy flows in an industrial district using an enterprise input-output model, Economic Systems Research, 15, pp. 457-480.

Aroche-Reyes, F. (2001) The question of identifying industrial complexes revisited: a qualitative perspective, in: M.L. Lahr and E. Dietzenbacher (eds), Input-Output Analysis: Frontiers and Extensions (Basingstoke: Palgrave Macmillan), pp. 280296.

\footnotetext{
${ }^{10}$ Of course, a quantification of such effects requires a more detailed analysis and a full specification of the shock. See, for example, the contributions on "disaster input-output analysis" in Okuyama and Chang (2004).
} 
Batey, P.W.J. and Rose, A.Z. (1990) Extended input-output models: progress and potential, International Regional Science Review, 13, pp. 27-50.

Beyers, W.B. (1976) Empirical identification of key sectors: some further evidence, Environment and Planning A, 8, pp. 231-236.

Beyers, W.B. (1983) The interregional structure of the US economy, International Regional Science Review, 8, pp. 213-231.

Blin, J.-M. and Murphy, F. (1974) On measuring economic interrelatedness, Review of Economic Studies, 41, pp. 437-440.

Burt, R. (1992) Structural Holes: The Social Structure of Competition (Cambridge, MA: Harvard University Press).

Cai, J. and Leung, P. (2004) Linkage measures: a revisit and a suggested alternative, Economic Systems Research, 16, pp. 65-85.

Davis, H.C. and Salkin, E.L. (1984) Alternative approaches to the estimation of economic impacts resulting from supply constraints, Annals of Regional Science, 18, pp. 2534.

Defourney, J. and Thorbecke, E. (1984) Structural path analysis and multiplier decomposition within a social accounting matrix framework, Economic Journal, 94, pp. 111-136.

de Mesnard, L. (1995) A note on qualitative input-output analysis, Economic Systems Research, 7, pp. 439-445.

de Mesnard, L. (2001) On Boolean topological methods of structural analysis, in: M.L. Lahr and E. Dietzenbacher (eds), Input-Output Analysis: Frontiers and Extensions (Basingstoke: Palgrave Macmillan), pp. 268-279.

Dietzenbacher, E. (1992) The measurement of interindustry linkages: key sectors in the Netherlands, Economic Modelling, 9, pp. 419-437.

Dietzenbacher, E. (1997) In vindication of the Ghosh model: a reinterpretation as a price model, Journal of Regional Science, 37, pp. 629-651.

Dietzenbacher, E. and Lahr, M.L. (2001) Introduction, in: M.L. Lahr and E. Dietzenbacher (eds), Input-Output Analysis: Frontiers and Extensions (Basingstoke: Palgrave Macmillan), pp. 1-31.

Dietzenbacher, E. and van der Linden, J.A. (1997) Sectoral and spatial linkages in the EC production structure, Journal of Regional Science, 37, pp. 235-257.

Dietzenbacher, E., van der Linden, J.A. and Steenge, A.E. (1993) The regional extraction method: EC input-output comparisons, Economic Systems Research, 5, pp. 185206.

Dietzenbacher, E., Romero Luna, I. and Bosma, N.S. (2005) Using average propagation lengths to identify production chains in the Andalusian economy, Estudios de Economía Aplicada, 23, pp. 405-422. 
Dietzenbacher, E., Smid, B. and Volkerink, B. (2000) Horizontal integration in the Dutch financial sector, International Journal of Industrial Organization, 18, pp. 12231242.

Duarte, R., Sánchez-Chóliz, J. and Bielsa, J. (2002) Water use in the Spanish economy: an input-output approach, Ecological Economics, 43, pp. 71-85.

Eurostat (1979) European System of Integrated Economic Accounts - ESA, 2nd edition (Luxembourg: Eurostat).

Flath, D. (1993) Shareholding in the keiretsu, Japan's financial groups, Review of Economics and Statistics, 75, pp. 249-257.

Fukui, Y. (1986) A more powerful method for triangularizing input-output matrices and the similarity of production structures, Econometrica, 54, pp. 1425-1433.

Ghosh, A. (1958) Input-output approach in an allocation system, Economica, 25, pp. 5864.

Groenewold, N., Hagger, A.J. and Madden, J.R. (1987) The measurement of industry employment contribution in an input-output model, Regional Studies, 21, pp. 255263.

Groenewold, N., Hagger, A.J. and Madden, J.R. (1993) Measuring industry importance: an Australian application, Annals of Regional Science, 27, pp. 175-182.

Grubbström, R.W. and Ovrin, P. (1992) Intertemporal generalization of the relationship between material requirements planning and input-output analysis, International Journal of Production Economics, 26, pp. 311-318.

Grubbström, R.W. and Tang, O. (2000) An overview of input-output analysis applied to production inventory systems, Economic Systems Research, 12, pp. 3-25.

Haltia, O. (1992) A triangularization algorithm without ringshift permutation, Economic Systems Research, 4, 223-234.

Harthoorn, R. (1988) On the Integrity of Data and Methods in the Static Open Leontief Model (Enschede, The Netherlands, University of Twente, Faculty of Public Administartion and Public Policy, PhD Thesis).

Hewings, G.J.D. (2001) New goals for new rural policies, International Regional Science Review, 24, pp. 146-160.

Hoen, A.R. (2002a) Identifying linkages with a cluster-based methodology, Economic Systems Research, 14, pp. 131-146.

Hoen, A.R. (2002b) An Input-Output Analysis of European Integration (Amsterdam: North-Holland).

Howe, E.C. (1991) A more powerful method for triangularizing input-output matrices: a commnet, Econometrica, 59, pp. 521-523.

Jones, L.P. (1976) The measurement of Hirschmanian linkages, Quarterly Journal of Economics, 90, pp. 323-333. 
Jones, R.W. and Kierzkowski, H. (2005) International fragmentation and the new economic geography, North American Journal of Economics and Finance, 10, pp. $1-10$.

Joshi, S. (2000) Product-environmental life-cycle assessment using input-output techniques, Journal of Industrial Ecology, 3, pp. 95-120.

van der Linden, J.A. (1999) Interdependence and Specialisation in the European Union (University of Groningen, The Netherlands, Faculty of Economics, PhD Thesis).

van der Linden, J.A. and Oosterhaven, J. (1995) European Community intercountry input-output relations: construction method and main results for 1965-1985, Economic Systems Research, 7, pp. 249-69.

Loviscek, A.J. (1982) Industrial cluster analysis - backward or forward linkages?, Annals of Regional Science, 16, pp. 36-47.

Madden, M. and Trigg, A.B. (1990) Interregional migration in an extended input-output model, International Regional Science Review, 13, pp. 65-85.

Marangoni, G. and Fezzi, G. (2002) I-O for management control: the case of GlaxoSmithKline, Economic Systems Research, 14, pp. 245-256.

Miller, R.E. (1966) Interregional feedback effects in input-output models: some preliminary results, Papers of the Regional Science Association, 17, pp. 105-125.

Miller, R.E. (1969) Interregional feedbacks in input-output models: some experimental results, Western Economic Journal, 7, pp. 41-50.

Miller, R.E. and Blair, P.D. (1983) Estimating state-level input-output relationships from US multiregional data, International Regional Science Review, 8, pp. 233-254.

Miller, R.E. and Lahr, M.L. (2001) A taxonomy of extractions, in: M.L. Lahr and R.E. Miller (eds), Regional Science Perspectives in Economic Analysis - A festschrift in Memory of Benjamin H. Stevens (Amsterdam: North-Holland), pp. 407-441.

Okuyama, Y. and Chang, S.E. (eds) (2004) Modeling Spatial and Economic Impacts of Disasters (Berlin: Springer Verlag).

Olsen, J.A. (1992) Input-output models, directed graphs and flows in networks, Economic Modelling, 9, pp. 365-384.

Oosterhaven, J. (1988) On the plausibility of the supply-driven input-output model, Journal of Regional Science, 28, pp. 203-217.

Oosterhaven, J. (1989) The supply-driven input-output model: a new interpretation but still implausible, Journal of Regional Science, 29, pp. 459-465.

Oosterhaven, J. and Dewhurst, J.H.Ll. (1990) A prototype demo-economic model with an application to Queensland, International Regional Science Review, 13, pp. 51-64.

Paelinck, J., de Caevel, J. and Degueldre, J. (1965) Analyse quantitative de certaines phénomènes du développement régional polarisé: essai de simulation statique d'itéraires de propogation, in: Bibliothèque de l'Institut de Science Économique, No. 7, Problèmes de Conversion Economique: Analyses Théoriques et Etudes Appliquées (Paris: M.-Th. Génin), pp. 341-387. 
Polenske, K.R. (1997) Linked system of enterprise, regional, national input-output accounts for policy analysis, in: M. Chatterji (ed.), Regional Science: Perspectives for the Future (London: Macmillan), pp. 26-42.

Polenske, K.R. and Chen, X. (eds) (1991) Chinese Economic Planning and Input-Output Analysis (Hong Kong: Oxford University Press).

Polenske, K.R. and McMichael, F.C. (2002) A Chinese cokemaking process-flow model for energy and environmental analysts, Energy Policy, 30, pp. 865-883.

Robinson, S. and Markandya, A. (1973) Complexity and adjustment in input-output systems, Oxford Bulletin of Economics and Statistics, 35, pp. 119-134.

Sánchez-Chóliz, J. and Duarte, R. (2003) Production chains and linkage measures, Economic Systems Research, 15, pp. 481-494.

Schnabl, H. (1994) The evolution of production structures analysed by a multilayer procedure, Economic Systems Research, 6, pp. 51-68.

Schnabl, H. (2001) Structural development of Germany, Japan and the USA, 1980-1990: a qualitative analysis using minimal flow analysis (MFA), in: M.L. Lahr and E. Dietzenbacher (eds), Input-Output Analysis: Frontiers and Extensions (Basingstoke: Palgrave Macmillan), pp. 245-267.

Simpson, D. and Tsukui, J. (1965) The fundamental structure of input-output tables, an international comparison, Review of Economics and Statistics, 47, pp. 434-446.

Slater, P.B. (1978) The network structure of the United States input-output table, Empirical Economics, 3, pp. 49-70.

Sonis, M., Guo, J., Hewings, G.J.D. and Hulu, E. (1997a) Interpreting spatial economic structure: feedback loops in the Indonesian economy, 1980, 1985, Regional Science and Urban Economics, 27, pp. 325-342,

Sonis, M. and Hewings, G.J.D. (1998a) Economic complexity as network complication: multiregional input-output structural path analysis, Annals of Regional Science, 34, pp. 569-589.

Sonis, M. and Hewings, G.J.D. (1998b) Visualization of economic structure and structural change, Paper presented at the $12^{\text {th }}$ International Conference on InputOutput techniques, New York.

Sonis, M. and Hewings, G.J.D. (2001) Feedbacks in input-output systems: impacts, loops and hierarchies, in: M.L. Lahr and E. Dietzenbacher (eds), Input-Output Analysis: Frontiers and Extensions (Basingstoke: Palgrave Macmillan), pp. 71-99.

Sonis, M., Hewings, G.J.D. and Gazel, R. (1995) An examination of multi-regional structure: hierarchy, feedbacks and spatial linkages, Annals of Regional Science, 29, pp. 409-430.

Sonis, M., Hewings, G.J.D. and Haddad, E. (1996) A typology of propagation of changes on the structure of a multiregional economic system: the case of the European Union, 1975-1985, Annals of Regional Science, 30, pp. 391-408. 
Sonis, M., Hewings, G.J.D. and Sulistyowati, S. (1997b) The structure of the Indonesian economy: a generalized structural path analysis, Economic Systems Research, 9, pp. 265-280.

Strassert, G. (1968) Zur Bestimmung strategischer Sektoren mit Hilfe von Input-Output Modellen, Jahrbücher für Nationalökonomie und Statistik, 182, pp. 211-215.

Tang, X., Elbrond, J. and Li, X. (1994) Some applications of input-output analysis in a gold mine, Economic Systems Research, 6, pp. 435-447.

Turnovec, F. (1999) Privatization, ownership structure, and transparency: how to measure the true involvement of the state, European Journal of Political Economy, 15, pp. 605-618.

Yan, C.S. and Ames, E. (1965) Economic interrelatedness, Review of Economic Studies, 32, pp. 299-310. 
Table 1. Average and maximum APLs

\begin{tabular}{|lcc|}
\hline & Average & Maximum \\
\hline Germany & 2.03 & 3.37 \\
France & 1.87 & 3.39 \\
Italy & 1.94 & 3.47 \\
The Netherlands & 1.83 & 3.26 \\
Belgium & 1.65 & 3.26 \\
Denmark & 1.79 & 3.14 \\
\hline Aggregate & 2.06 & 3.57 \\
\hline
\end{tabular}


Table 2. APLs for the aggregate case

\begin{tabular}{|crrrrrrrrr|}
\hline & AG & EN & ME & AM & OM & BU & MS & PS & Avrg \\
\hline AG & 1.48 & 3.49 & 3.57 & 1.60 & 2.58 & 3.45 & 2.54 & 2.61 & 2.67 \\
EN & 2.01 & 1.31 & 2.15 & 2.34 & 1.84 & 2.39 & 1.88 & 1.93 & 1.98 \\
ME & 2.39 & 1.94 & 1.53 & 2.62 & 2.14 & 1.74 & 2.12 & 1.91 & 2.05 \\
AM & 1.70 & 2.80 & 2.57 & 1.56 & 2.11 & 2.71 & 1.84 & 1.79 & 2.13 \\
OM & 1.92 & 2,20 & 2.01 & 2.17 & 1.46 & 1.54 & 2.41 & 1.95 & 1.96 \\
BU & 2.16 & 1.47 & 2.45 & 2.68 & 2.42 & 1.40 & 1.51 & 1.38 & 1.93 \\
MS & 2.15 & 1.88 & 1.99 & 2.08 & 1.95 & 1.85 & 1.51 & 1.82 & 1.91 \\
PS & 2.03 & 1.76 & 2.06 & 2.29 & 1.98 & 2.21 & 1.60 & 1.18 & 1.89 \\
\hline Avrg & 1.98 & 2.11 & 2.29 & 2.17 & 2.06 & 2.16 & 1.93 & 1.82 & 2.06 \\
\hline
\end{tabular}

$\mathrm{AG}=$ Agriculture $; \mathrm{EN}=$ Energy; $\mathrm{ME}=$ Metal-related manufacturing; $\mathrm{AM}=$ Agro-related manufacturing; $\mathrm{BU}=$ Building and construction; $\mathrm{OM}=$ Other manufacturing; $\mathrm{MS}=$ Market services; PS = Public services; Avrg = average. 
Table 3. Linkages between the industries

\begin{tabular}{|rrrrrrrrr|}
\hline & AG & EN & ME & AM & OM & BU & MS & PS \\
\hline AG & $\mathbf{0 . 1 3 3}$ & 0.004 & 0.034 & $\mathbf{0 . 4 7 7}$ & 0.040 & 0.011 & 0.117 & 0.054 \\
EN & 0.080 & $\mathbf{0 . 2 6 5}$ & $\mathbf{0 . 1 6 1}$ & 0.098 & $\mathbf{0 . 1 6 1}$ & 0.059 & $\mathbf{0 . 1 5 6}$ & 0.086 \\
ME & 0.033 & 0.044 & $\mathbf{0 . 4 4 5}$ & 0.033 & 0.049 & 0.084 & 0.052 & 0.065 \\
AM & 0.100 & 0.007 & 0.049 & $\mathbf{0 . 3 0 2}$ & 0.047 & 0.020 & 0.118 & 0.080 \\
OM & 0.061 & 0.016 & $\mathbf{0 . 1 4 5}$ & 0.082 & $\mathbf{0 . 3 2 8}$ & $\mathbf{0 . 1 9 4}$ & 0.061 & 0.083 \\
BU & 0.011 & 0.023 & 0.024 & 0.015 & 0.015 & 0.023 & 0.083 & 0.038 \\
MS & 0.111 & 0.070 & $\mathbf{0 . 2 2 1}$ & $\mathbf{0 . 1 7 3}$ & $\mathbf{0 . 1 8 2}$ & $\mathbf{0 . 1 5 7}$ & $\mathbf{0 . 3 5 9}$ & $\mathbf{0 . 1 3 6}$ \\
PS & 0.020 & 0.009 & 0.027 & 0.022 & 0.022 & 0.018 & 0.052 & $\mathbf{0 . 2 1 6}$ \\
\hline
\end{tabular}


Table 4. Relevant linkages and their distance

\begin{tabular}{|ccccccccc|}
\hline & AG & EN & ME & AM & OM & BU & MS & PS \\
\hline AG & 1 & 0 & 0 & 1 & 0 & 0 & 0 & 0 \\
EN & 0 & 1 & 2 & 0 & 1 & 0 & 1 & 0 \\
ME & 0 & 0 & 1 & 0 & 0 & 0 & 0 & 0 \\
AM & 0 & 0 & 0 & 1 & 0 & 0 & 0 & 0 \\
OM & 0 & 0 & 2 & 0 & 1 & 1 & 0 & 0 \\
BU & 0 & 0 & 0 & 0 & 0 & 0 & 0 & 0 \\
MS & 0 & 0 & 1 & 2 & 1 & 1 & 1 & 1 \\
PS & 0 & 0 & 0 & 0 & 0 & 0 & 0 & 1 \\
\hline
\end{tabular}


Table 5. The effect of extracting a country on average APLs

\begin{tabular}{|cccc|}
\hline $\begin{array}{c}\text { Extracted } \\
\text { country }\end{array}$ & $\begin{array}{c}\text { Before } \\
\text { extraction }\end{array}$ & $\begin{array}{c}\text { After } \\
\text { extraction }\end{array}$ & $\%$ \\
\hline Germany & 2.77 & 2.68 & -3.27 \\
France & 2.78 & 2.75 & -1.40 \\
Italy & 2.74 & 2.73 & -0.51 \\
Netherlands & 2.80 & 2.76 & -1.54 \\
Belgium & 2.88 & 2.83 & -1.65 \\
Denmark & 2.80 & 2.80 & -0.08 \\
\hline
\end{tabular}


Figure 1. Production chains in the six-country European economy

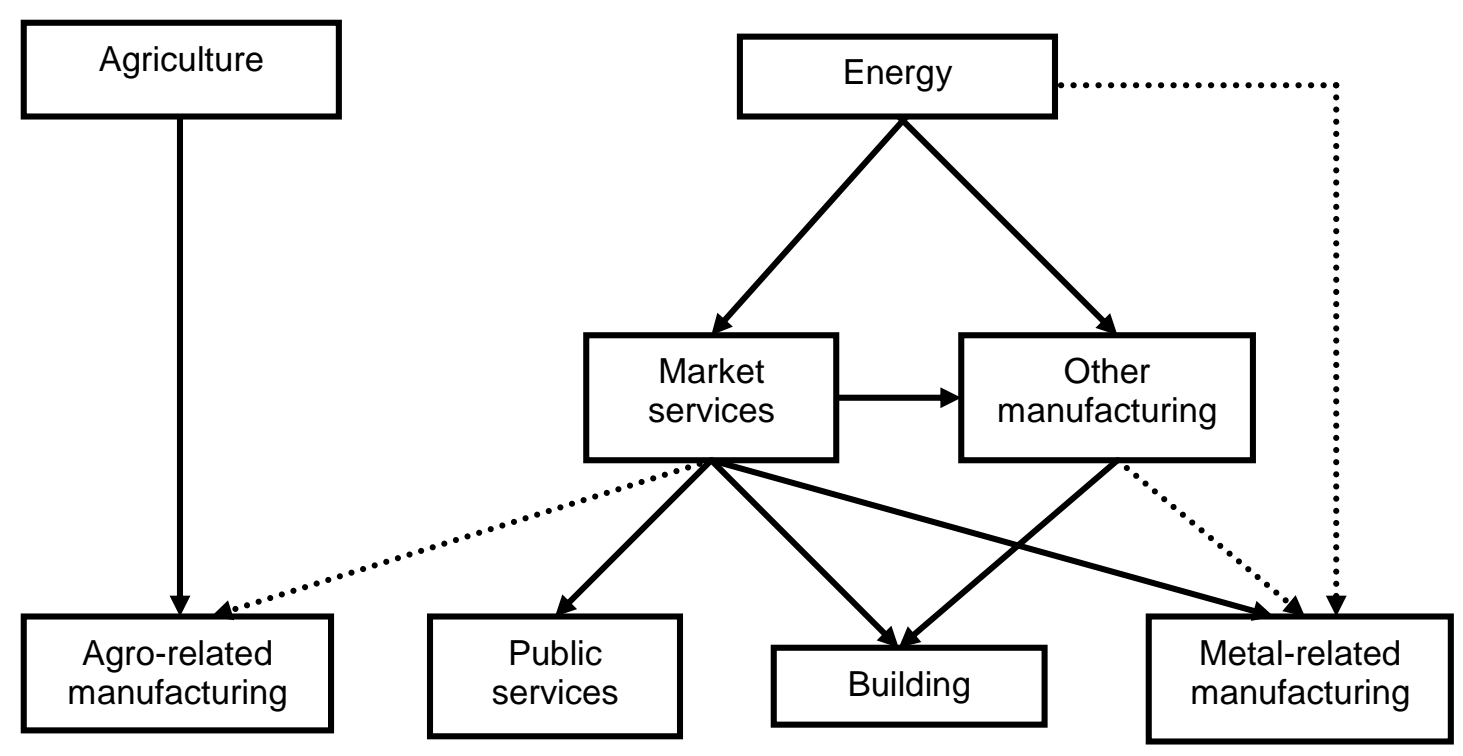


Figure 2. Main intercountry linkages using APLs

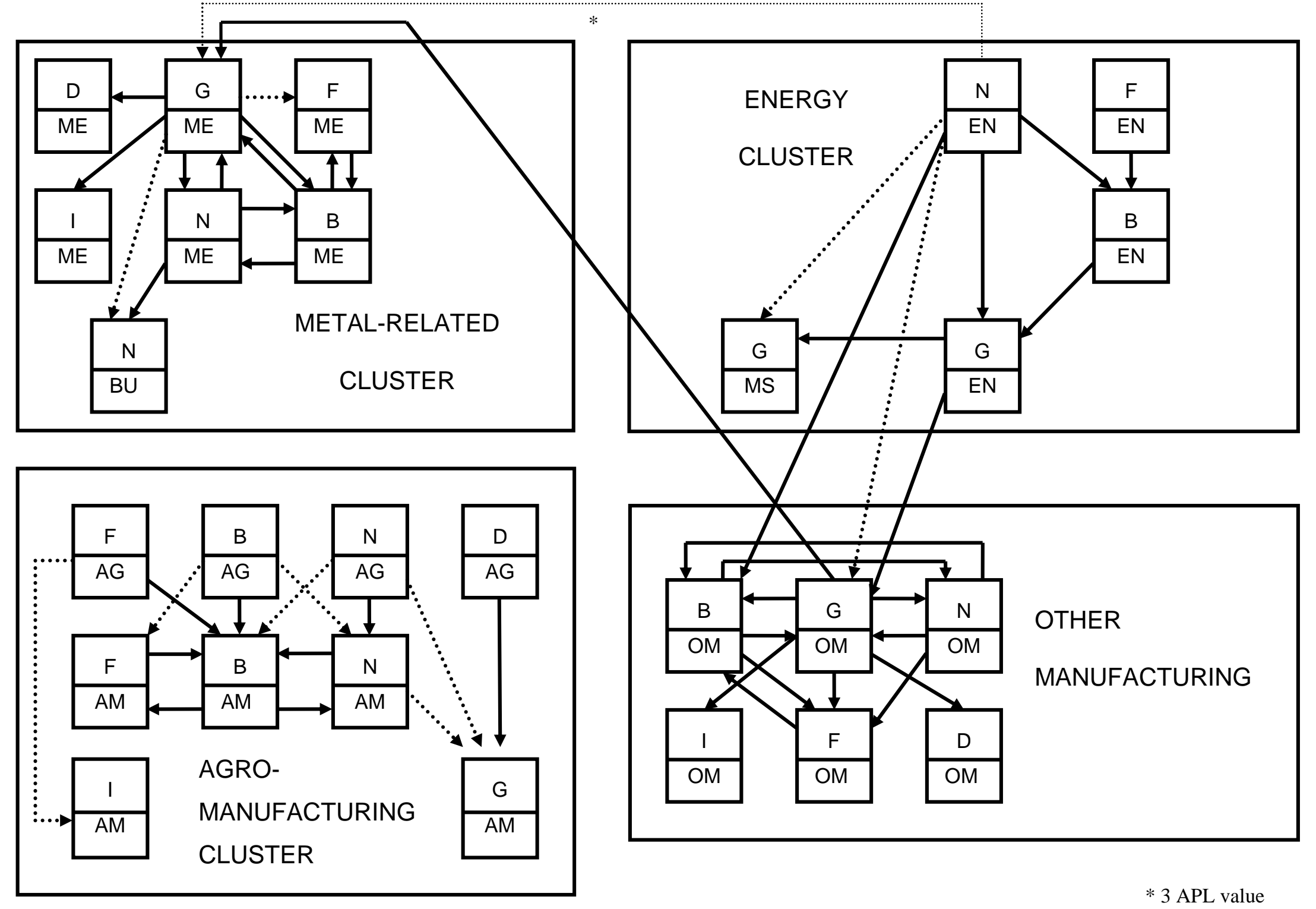


